\title{
Application of the Empirical Mode Decomposition method for the prediction of the tool wear in turning operation
}

\author{
Mohamed Khemissi Babouri*, Nouredine Ouelaa**, Abderrazek Djebala*** \\ *Mechanics and Structures Laboratory, May 08th 1945 University, P.B 401, Guelma 24000, Algeria \\ *Department of Mechanical Engineering and Productics (CMP), FGM \& GP, University of Sciences and Technology \\ Houari Boumediene, Po Box 32, El-Alia, Bab-Ezzouar, Alger, 16111, Algeria, E-mail:babouri_bmk@yahoo.fr \\ **Mechanics and Structures Laboratory, May 08th 1945 University, P.B 401, Guelma 24000, Algeria \\ E-mail: n_ouelaa@yahoo.fr \\ ***Mechanics and Structures Laboratory, May 08th 1945 University, P.B 401, Guelma 24000, Algeria \\ E-mail: djebala_abderrazek@yahoo.fr
}

cross $^{\text {ref }}$ http://dx.doi.org/10.5755/j01.mech.23.2.8971

\section{Nomenclature}

$a_{p}$ - depth of cut, mm; $f$ - feed rate, $\mathrm{mm} / \mathrm{rev} ; v_{c}$ - cutting speed, $\mathrm{m} / \mathrm{min} ; \quad t$-cutting time, $\min ; \quad E$ - energy; Pmoy - mean power; $T$ - tool life, min; IMFs - intrinsic mode functions; Amp-mplitude of frequency indicator; $F_{\text {in }}$ - frequency indicator, $\mathrm{Hz} ; \alpha$-relief angle, degree; $\gamma$ rake angle, degree; $\lambda$ - inclination angle, degree; $\chi$ - major cutting edge angle, degree

\section{Introduction}

Monitoring tool wear is a more complex task than expected, because it induces a very small process change with a large dynamic range. In the context of monitoring tool wear, many methods have been proposed. These methods are based on the analysis of various physical quantities that can be detected by direct control of the tool or by estimating its state by measuring another significant magnitude. Among these physical quantities the vibration signals [1, 2], acoustic emission [3-5], and the cutting forces $[6,7]$ have proven their efficiency and monitoring performance of tool wear. Similar work conducted by Rmili et al. [8] concentrates on treating the vibratory signature generated by machining. The adopted strategy is based on a temporal analysis using statistical parameters. Then, in the frequency domain using the periodogram method and smoothed averages. Coming fill the limits of the spectral analysis, wavelet analysis has been proposed as a timefrequency advanced method. The wavelet analysis enables a local visualization of the signal instead of the spectral analysis that allows only a global vision. Several applications of the wavelet analysis have been proposed in its continuous and discrete version [9-10]. The classification and prediction of the tool state with input data from one or more sensors and architectures of neural networks have been studied in $[11,12]$. In 1998 a new time-frequency method called Empirical Mode Decomposition (EMD) has been proposed by Huang [13]. The EMD is a self-adaptive decomposition of the signal contrary to the wavelet analysis that needs the use of an appropriate wavelet mother. In this context the objective of this work is to propose a new method for the cutting tool state supervision based on the vibratory signal's analysis using the EMD.

The aim of this paper is to propose the EMD as an effective tool allowing improving the sensitivity of the scalar indicators (Energy and Mean power) for tool wear detection. Indeed, these indicators are very sensitive to the variations in temporal signal. Nevertheless, their reliability is immediately limited by the presence of high level of random noise. Empirical Mode Decomposition is proposed as a solution to this problem.

\section{Lifespan of tool wear}

The life of cutting tool represents the actual productive time during which the cutting edge is directly related to the wear. The wear manifests on the cutting tool in several forms dependent cutting conditions, the material being machined, the material of the cutting tool and its geometry. In normal conditions, flank wear (VB) is considered to assess the predominant wear to evaluate the lifespan of the cutting tool [14]. The development of this type of wear on the cutting tool is not a random phenomenon. The appearance (Fig. 1) drawn below is divided into three zones: break-in (A), wear stabilization (B) and accelerated wear $(\mathrm{C})$. The objective of any monitoring and prediction system is the early detection of the transition point form the stabilization zone to the wear accelerated zone.

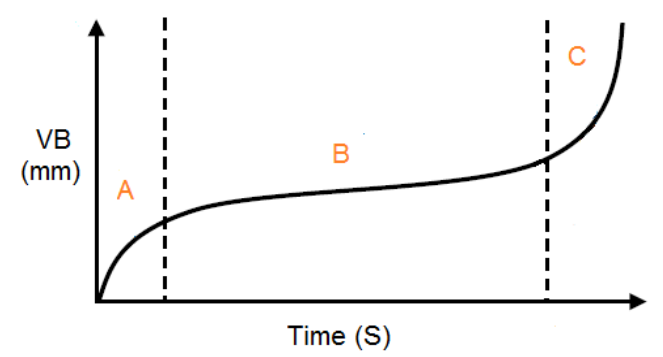

Fig. 1 Evolution of flank wear with time

\section{Empirical Mode Decomposition}

The EMD is defined by a process called screening (sifting) to decompose the signal in core contributions called empirical modes or IMF (Intrinsic mode functions). Decomposition is local, iterative, sequential and entirely data-driven. The primary objective of the EMD is to extract a non-stationary signal from systems that can be non-linear patterns that lend themselves to a time-frequency analysis; where Fourier analysis and wavelets are sometimes ineffective. It indeed makes the time-frequency representation more readable and clean physical interpretation. The princi- 
ple of the EMD decomposition is provided by the screening process set by the algorithm described in the following. The Fig. 2 shows the principle of EMD (decomposition of signals in different modes: IMFs).

The IMFs is an innovation proposed by Huang [13] in the empirical mode decomposition, which is definedas a function which satisfies the following steps:

- In the whole data set, the number of extrema and the number of zero-crossings must either equal or differ at most by one;

- At any point, the mean value of the envelope defined by local maxima and the envelope defined by the local minima is zero.

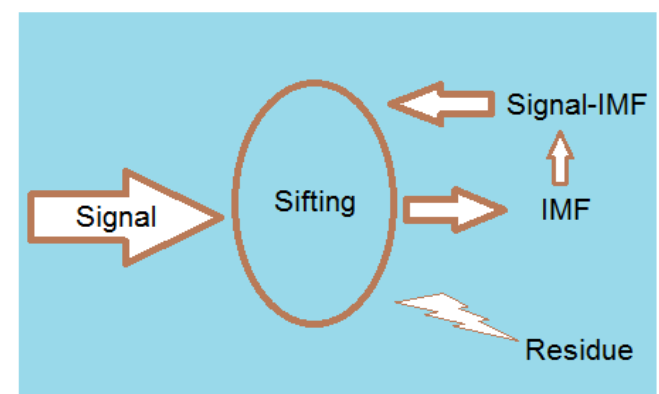

Fig. 2 Principle of Empirical Mode Decomposition

The IMF represents the simple oscillation mode involved in the signal $s(t)$. Empirical mode decomposition is a sifting process used to extract the IMFs by the following steps:

1. Identify all the local extrema, and connect all the local maxima by a cubic spline line as the upper envelope;

2. Repeat the procedure on the local minima to produce the lower envelope;

3. Designate the mean of upper and lower envelope value as $\mathrm{m}_{1}$, and the difference between the signal $x(t)$ and $m_{1}$ is the first component $h_{1}$, i.e.:

$$
x(t)-m_{1}=h_{1} ;
$$

$x(t)$

If $h_{1}$ is an IMF, then $h_{1}$ is the first IMF of signal

4. If $h_{1}$ is not an IMF, take it as the original signal and repeat the steps (1), (2), (3) until $h_{1 k}$ becomes an IMF.

$$
\begin{aligned}
& h_{1(k-1)}-m_{1 k}=h_{1 k} ; \\
& c_{1}=h_{1 k} ;
\end{aligned}
$$

5. Separate $c_{1}$ from $x(t)$ by:

$$
r_{1}=x(t)-c_{1}
$$

6. Treat residue $r_{1}$ as the original signal and repeat processes as described above $n$ Times, so that we can get other $n-I M F s$ of signal $x(t)$. Then:

$$
\begin{gathered}
r_{1}-c_{2}=r_{2} \\
\vdots \\
r_{n-1}-c_{n}=r_{n}
\end{gathered}
$$

tain:

7. By summing up Eqs. (5) and (6), we finally ob-

$$
x(t)=\sum_{i=1}^{n} c_{i}+r_{n}
$$

Fig. 3 shows an example of EMD analysis of a vibratory signal measured in radial direction. The signal is decomposed into fifteen IMFs and a residue.
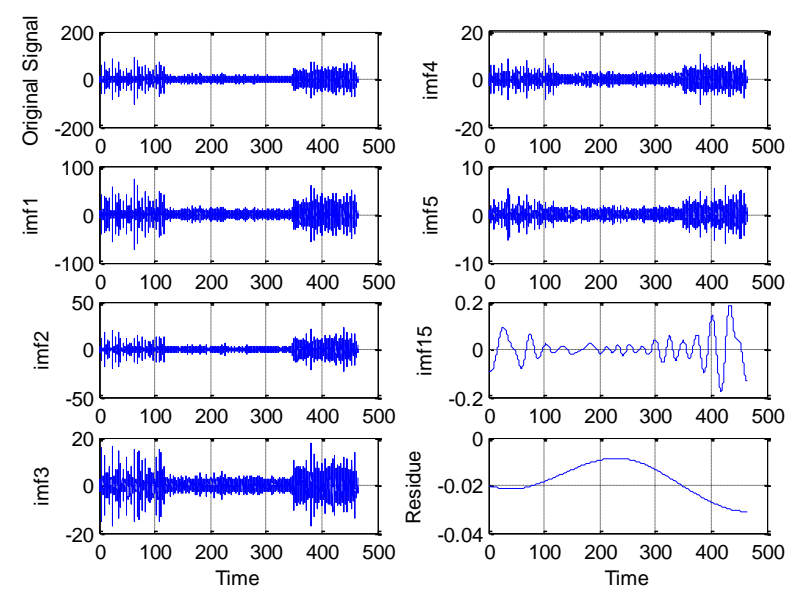

Fig. 3 Original signal and its decomposition with EMD

\section{Experimental validation}

\subsection{Machining testing device}

The lathe used for machining operations is TOS TRENCIN; model SN40C, spindle power 6.6KW. The specimens are made of high chromium grade X200Cr12 (AISI D3). This steel has an excellent wear resistance, usually used for the production of dies and punches for cutting and stamping, profiling rollers, and combs rolling nets. For testing, we machined specimens of diameter $\Phi=80 \mathrm{~mm}$ and length $L=400 \mathrm{~mm}$, the toolholder adapted is of designation PSDNN 2525 M12 with the active part geometry characterized by the following angles: $\chi=75^{\circ} ; \alpha=6^{\circ}$; $\gamma=-6^{\circ} ; \lambda=-6^{\circ}[15]$. The cutting insert used is a coated carbide $\mathrm{TiCN} / \mathrm{Al}_{2} \mathrm{O}_{3} / \mathrm{TiN}$ removable, of square form with eight cutting edges. Cutting operations were conducted without applying cutting fluid, and all cutting tests were performed under the following cutting conditions: cutting speed $=250 \mathrm{~m} / \mathrm{min}$; feed rate $=0.12 \mathrm{~mm} / \mathrm{rev}$; and depth of cut $=0.20 \mathrm{~mm}$.

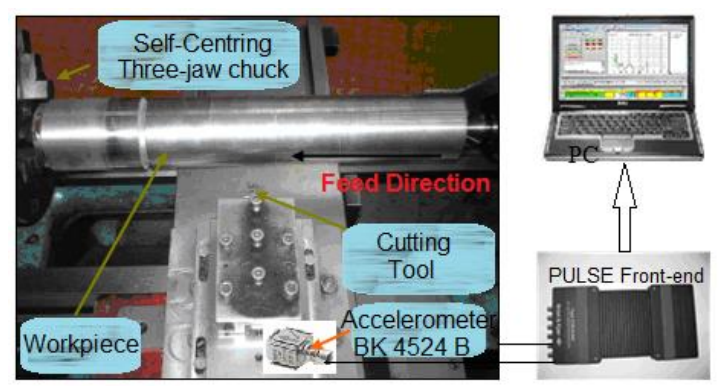

Fig. 4 Device used to measure the vibratory signals

The acquisition of vibration signals is performed by triaxial piezoelectric accelerometers, Brüel \& Kjaer type 4524B. The acceleration signals are acquired during 
periods of 116 seconds on the observation's three channels $(x, y, z)$, taken at a sampling frequency of $7000 \mathrm{~Hz}$. Each signal contained 16384 samples. The collected data were stored directly on the PC using an acquisition and analysis system controlled by Pulse Lab shop ${ }^{\circledR}$ software developed by Brüel \& Kjaer (Fig. 4).

\subsection{Experimental modal analysis}

The experimental modal analysis with impact excitation has the advantage of being relatively simple to implement. Prior to the completion of the machining tests, one first determined the natural modes of the cutting tool in the main directions by one of the simplest and fastest method. It consists in exciting the system by means of a hammer of instrumented impact, and the response is detected using a piezoelectric accelerometer.

The accelerometer used was fixed by adhesive pads on the peripheral portion of the cutting tool to identify vibratory responses during cutting operation. The impact excitation's directions are perpendicular to the surfaces of the tool as shown in Fig. 5. During these experiments and to obtain the system's natural frequencies, the tool is mounted on the machine under the real experimental machining conditions. The acquisition was performed with a bandwidth of $12.8 \mathrm{kHz}$ to cover the entire spectrum of the system.

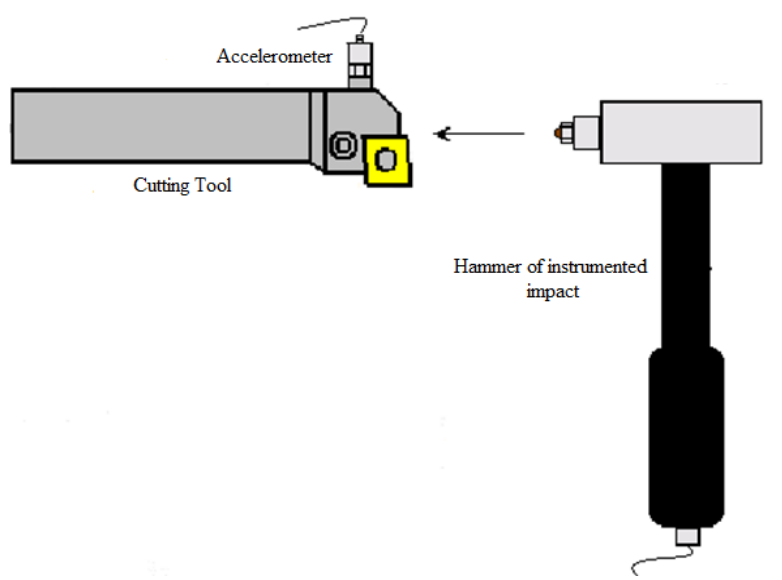

Fig. 5 Experimental device used for modal analysis

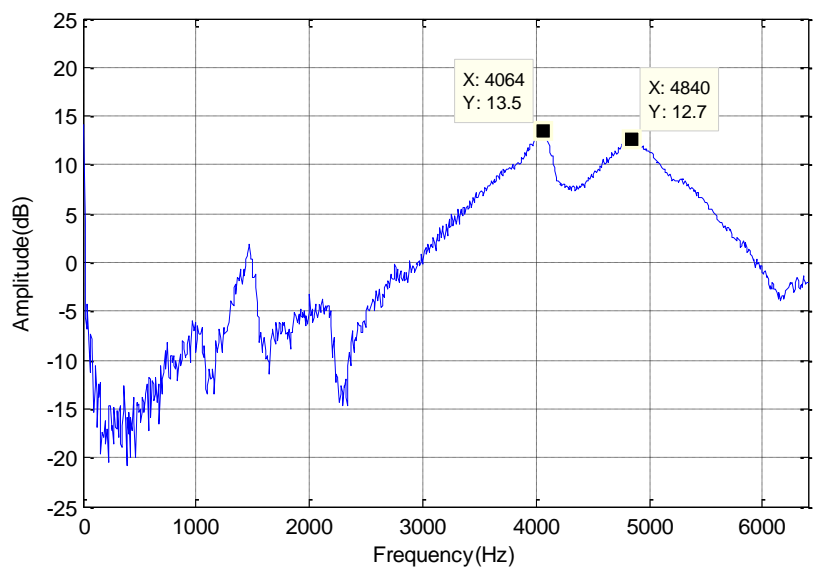

Fig. 6 Autospectra of the cutting tool

According to Fig. 6 the tool's natural modes are clearly shown around $2000 \mathrm{~Hz}$, between 4100 and $4800 \mathrm{~Hz}$. The results obtained by the modal analysis will be taken into account in the interpretation of the results obtained during machining tests.

\subsection{Vibration's answers and evolution of flank wear $V B$}

The machining tests were performed without lubrication. The tests stop when the flank wear $(V B)$ reaches or exceeds the value of $0.3 \mathrm{~mm}$, which is synonymous of the lifespan of the cutting insert. At this value, the insert is in the acceleration phase corresponding to a critical zone of the machining quality.

Fig. 7 shows an example of a concatenation of vibration acceleration signals over the entire service life of the cutting tool. According to these responses one observe that there are three main phases of the cutting tool life: wear up period, wear stabilization period, and wear acceleration period where the rapid aging of the tool occurs.

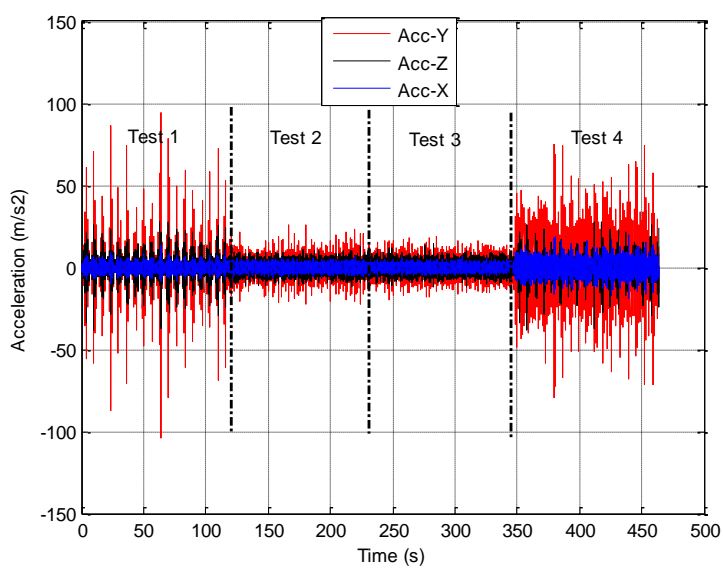

Fig. 7 Evolution of flank wear according to the time of machining over all the tool's lifespan for the three cutting directions

Note that the transition to the wear acceleration phase is detectable in the direction (y) (in red), this observation is the same on all acquisitions. The analysis tends to allow the detection of the transition region of the stabilization phase before the accelerated wear phase. The importance of determining this transition point is fundamentally linked to the beginning of tool aging before its total collapse and then the machining fail.
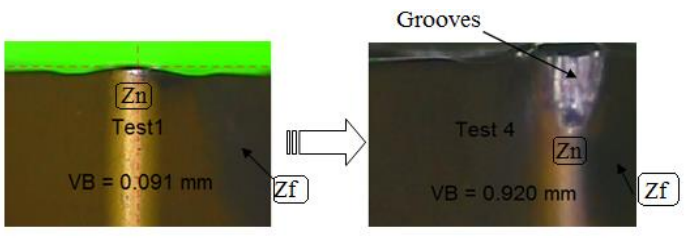

Fig. 8 Microphotos of coated carbide insert flank wear (Zn: insert nose zone, Zf: flank face zone)

The experimental results of the morphology of the flank wear are presented in Fig. 8. The analysis of these results shows that the cutting speed has an important influence on the wear. On the rock surface the wear is irregular, it is enlarged with time. It grows in length and width, this corresponds to a critical transition point of the tool life, which weakens the cutting edge and then the collapse of the tool nose at the end of machining after $8 \mathrm{~min}$ where $V B=0.920 \mathrm{~mm}$. 


\section{Proposed approach}

The method of Empirical Mode Decomposition is applied to the measured signals. As result, one obtains several Intrinsic Mode Functions (IMF) and a residue as shown in Fig. 3. The EMD method is acting as a set of filters and decomposes the original vibration signal into several bandwidths. Therefore, the EMD method decomposes the signal starting from the high frequencies to low frequencies. The centralization of energies in the first IMFs corresponding to high frequencies are also high (see Fig. 3).

Since the obtained IMFs and residue should be an orthogonal representation of the inspected signal, suitable IMFs should have a strong correlation with the signal, while irrelevant IMFs have low correlation with the signal.

For this raison the first IMF is selected as a reconstructed signal since it contains the most important energy. Moreover the cutting tool phenomenon is generally monitored at high frequencies at level of the tool's natural frequencies.

This result is confirmed by the Table 1 where the energy and the mean power of the IMF1 are most important compared to those of IMF2 and IMF3. Moreover Table 2 shows that the energy and the mean power change with flank wear and may reflect the tool life's periods.

Fig. 9 shows the energy and the mean power calculated for the reconstructed signal (IMF1) for the entire tool's lifespan. The tool's three life periods are clearly detectable. The breaking-in period ranges between $0 \mathrm{~s}$ and $120 \mathrm{~s}$, the two indicators are important. The stabilization period ranges between $120 \mathrm{~s}$ and $340 \mathrm{~s}$; in this case the energy and the mean power are almost stable.

Finally the wear acceleration period starts from $340 \mathrm{~s}$ where the two scalar indicators increase one more time. The more important result obtained is that the transition point from the wear stabilization and the wear acceleration periods is very clear. This is crucial information allowing the prediction of the tool aging before its total collapse and then the machining fail.

Table 1

Energy and mean power of the first three IMFs

\begin{tabular}{|c|c|c|c|}
\hline Indicator & IMF1 & IMF2 & IMF3 \\
\hline$E$ & $5.147 \mathrm{E}+006$ & $4.274 \mathrm{E}+005$ & $2.641 \mathrm{E}+005$ \\
\hline Pmoy & $9.818 \mathrm{E}+005$ & $8.153 \mathrm{E}+004$ & $5.037 \mathrm{E}+004$ \\
\hline
\end{tabular}

Table 2

Energy and mean power of the first three IMFs according to flank wear $(V B)$

\begin{tabular}{|c|c|c|c|c|}
\hline Ind & $V B_{1}=0.091$ & $V B_{2}=0.218$ & $V B_{3}=0.359$ & $V B_{4}=0.920$ \\
\hline$E_{I M F 1}$ & $\mathbf{1 . 5 8 E + 0 6}$ & $\mathbf{3 . 5 9 E + 0 5}$ & $\mathbf{3 . 0 9 E + 0 5}$ & $\mathbf{3 . 2 6 E + 0 6}$ \\
\hline$E_{I M F 2}$ & $1.18 \mathrm{E}+05$ & $1.84 \mathrm{E}+04$ & $2.13 \mathrm{E}+04$ & $1.27 \mathrm{E}+05$ \\
\hline$E_{I M F 3}$ & $8.62 \mathrm{E}+04$ & $1.91 \mathrm{E}+04$ & $1.70 \mathrm{E}+04$ & $7.74 \mathrm{E}+04$ \\
\hline$P_{m o y}^{I M F 1}$ & $\mathbf{1 . 2 0 E + 0 6}$ & $\mathbf{2 . 7 4 E + 0 5}$ & $\mathbf{2 . 3 6 E + 0 5}$ & $\mathbf{2 . 4 9 E + 0 6}$ \\
\hline$P_{\text {moy }}^{I M F 2}$ & $8.98 \mathrm{E}+04$ & $1.40 \mathrm{E}+04$ & $1.63 \mathrm{E}+04$ & $9.71 \mathrm{E}+04$ \\
\hline$P_{m o y}^{I M F 3}$ & $6.57 \mathrm{E}+04$ & $1.46 \mathrm{E}+04$ & $1.30 \mathrm{E}+04$ & $5.90 \mathrm{E}+04$ \\
\hline
\end{tabular}

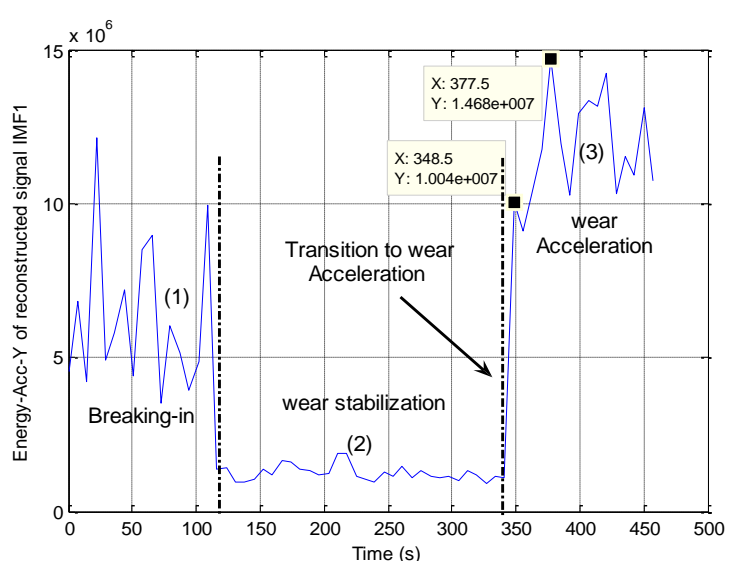

a

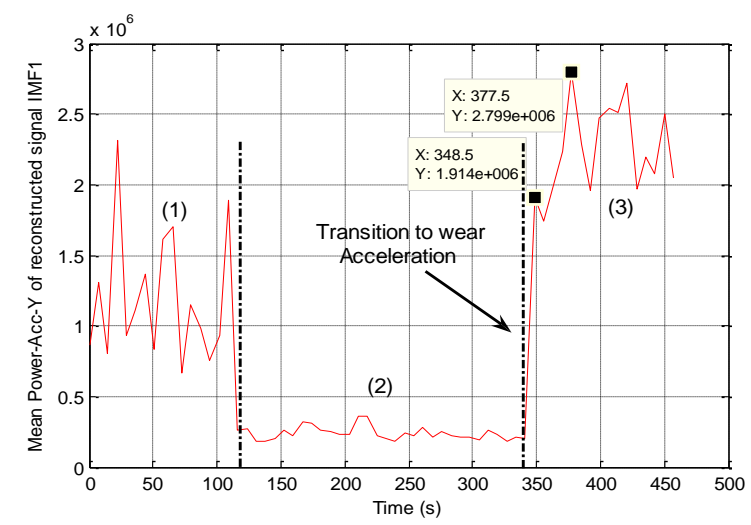

b

Fig. 9 Mean power and energy after the application of EMD: a - Energy; b - Mean Power

\section{Frequency indicator of the reconstructed signals}

Each IMF has its own spectrum in a specific frequency band (characteristic frequency). These spectra cover all the tool life from the first test to the end of the tool lifespan. According to the spectra of IMF1 (Fig. 10), one distinguish the first tool's mode at $2000 \mathrm{~Hz}$ and the second mode appearing in the frequency band [4000-5000] Hz.

These modes have been previously identified by the modal analysis in section (4.2). The amplitudes of the peak corresponding to the second natural frequency [4000-5000] Hz are very significant and contain a very high energy level. Therefore, a new spectral indicator is proposed. It allows the monitoring of the wear by visualizing the amplitude variation of the peak corresponding to the natural frequency of the tool between 4000 and $5000 \mathrm{~Hz}$.

The analysis of this new indicator shows an increase in the amplitude that depends on the cutting tool wear phases. In the first phase corresponding to the abrasive wear (Fig. 10, a) this frequency indicator's amplitude is $A m p_{1}=1.067 \mathrm{e}+004$ and $F_{i n 1}=4713 \mathrm{~Hz}$ with lifetime $T_{1}=1.93 \mathrm{~min}$ and flank wear $V B_{1}=0.091 \mathrm{~mm}$. Note that in this phase the reconstructed signal highlights a periodical impacts spaced with $5.8 \mathrm{~s}$ that probably correspond to the phenomenon of chattering.

In the second phase of wear stabilization (Fig. 10, b and c), the amplitude decreases and remains almost constant with the following values: Amp $2-3=3909 \div 4318$ and $F_{\text {in } 2-3}=4756 \div 4916 \mathrm{~Hz}$, with $T_{2-3}=3.86 \div 5.8 \mathrm{~min}$ and $V B_{2-3}=0.218 \div 0.359 \mathrm{~mm}$. 

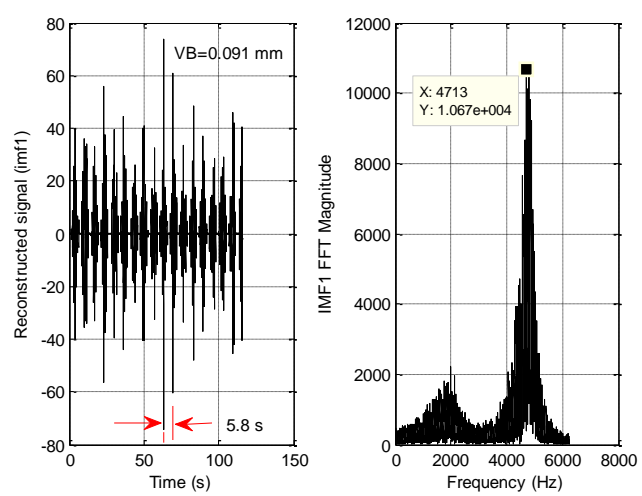

a
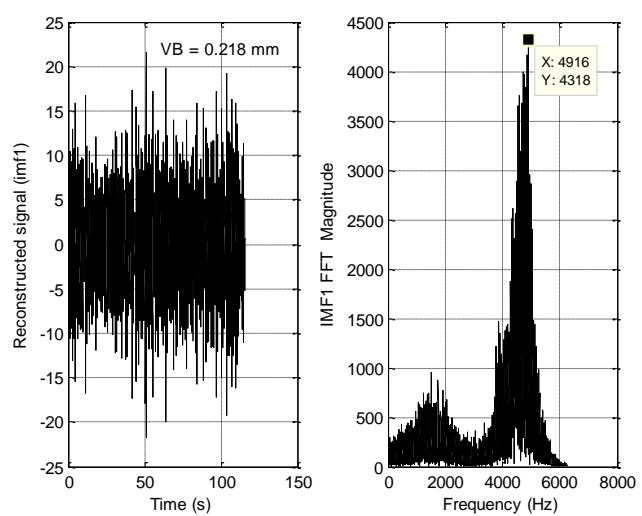

b
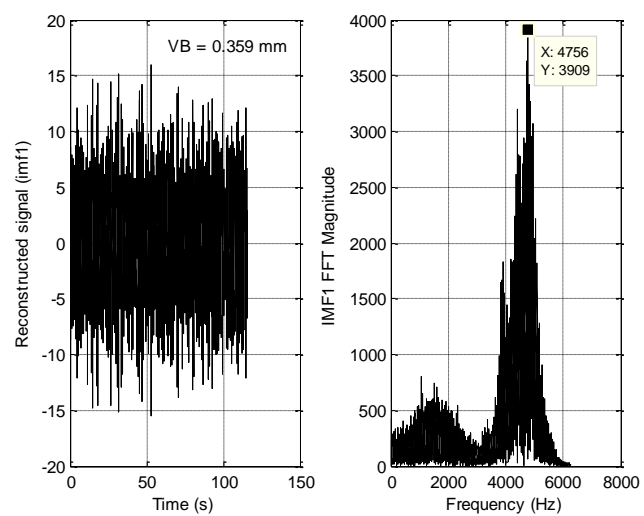

$\mathrm{c}$
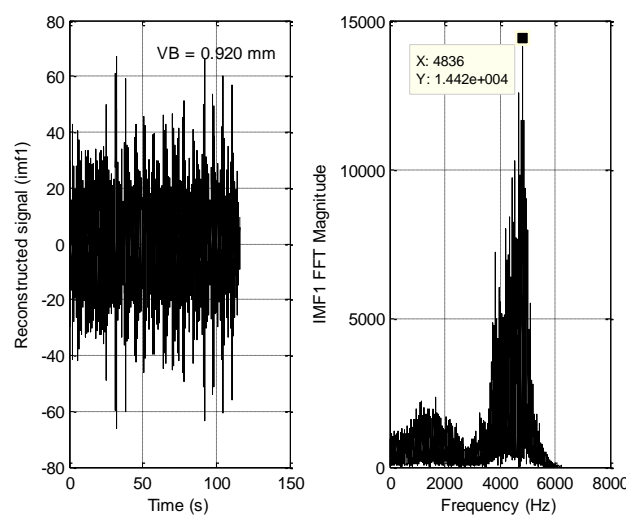

d

Fig. 10 IMF1 and its spectra for different configurations: $\mathrm{a}-V B=0.091 \mathrm{~mm} ; \quad \mathrm{b}-V B=0.218 \mathrm{~mm} ; \quad \mathrm{c}-V B=$ $=0.359 \mathrm{~mm} ; \mathrm{d}-V B=0.920 \mathrm{~mm}$

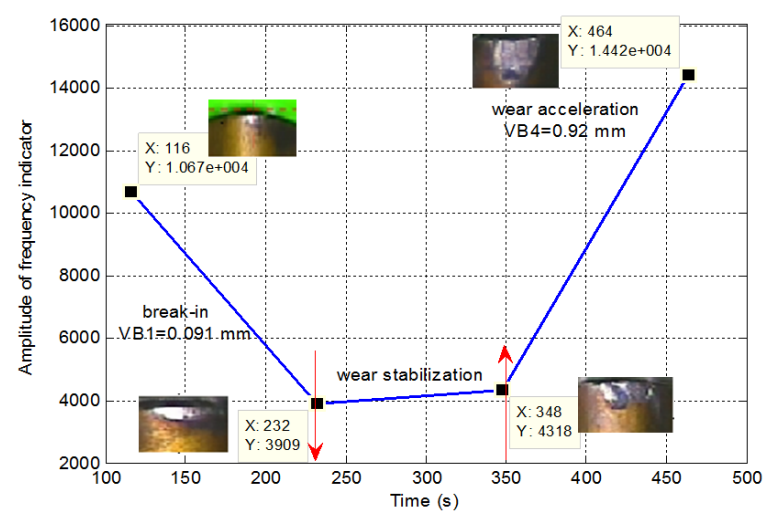

Fig. 11 Frequency indicator variation over the tool life

Finally in the last phase corresponding to the wear acceleration (Fig. 10, d), the frequency indicator considerably increases and reaches a very important value of $A m p_{4}=1.442 \mathrm{e}+004$ and $F_{i n 4}=4836 \mathrm{~Hz}$, with $T_{4}=7.7 \mathrm{~min}$ and $V B_{4}=0.920 \mathrm{~mm}$.

As conclusion, Fig. 11 shows that the frequency indicator's amplitude varies in a very similar way as the energy and the mean power variation (see Fig. 9). It clearly shows the three periods of the tool life allowing, especially, the detection of the transition point form the stabilization period to the wear acceleration period.

\section{Conclusion}

This article proposes the application of a new time-frequency method, called Empirical Mode Decomposition, for the prediction of the tool wear via vibratory signals measured during the cutting process in turning operation.

The tests of slide-lathing carried out on grade AISI D3 steel, machined by a coated carbide tool (insert $\mathrm{TiCN} / \mathrm{Al}_{2} \mathrm{O}_{3} / \mathrm{TiN}$ ), enabled us to study the tool lifespan and to extract the vibratory signature that reflects the tool state during its life allowing a clear detection. Using the sifting process to decompose the raw signal into several Intrinsic Modes Functions, it was possible to detect the critical transition point from the wear stabilization period to the wear acceleration period and then to predict the tool ageing and avoid its collapse and the machining fail.

A time domain analysis has been carried out using two scalar indicators; the energy and the mean power of the IMF1. The variation of these indicators over the entire tool life highlights the three periods and locates the beginning of the tool ageing. In the frequency domain, a new indicator was proposed; the amplitude of the peak corresponding to the tool natural frequency. The variation of this new indicator over the entire tool life also highlights its three periods and locates the critical transition point.

Finally it is to be noted that the vibratory signature in the radial direction is the most significant and very sensitive to the cutting conditions. The most distinguished wear phenomenon is abrasion that appears by grooving on the tool flank face. The abrasion is due to pull out of tool particles by hard particles existing in the machined material.

\section{Acknowledgements}

This work was completed in the laboratory LMS (University of Guelma, Algeria). The authors would like to 
thank the Algerian Ministry of Higher Education and Scientific Research (MESRS) and the Delegated Ministry for Scientific Research (MDRS) for granting financial support for CNEPRU Research Project - LMS: N_J0301520130034 (University 08 May 1945, Guelma).

\section{References}

1. Lim, G.H. 1995. Tool wear monitoring in machine turning, Materials Processing Technology 51: 25-36. http://dx.doi.org/10.1016/0924-0136(94)01354-4.

2. Mahfouz, I.A. 2003. Drilling wear detection and classification using vibration signals and artificial neural network, Machine Tools \& Manufacture 43: 707-720. http://dx.doi.org/10.1016/S0890-6955(03)00023-3.

3. Pontuale, G.; Farrelly, F.A.; Petri, A.; Pitolli, l. 2003. A statistical analysis of acoustic emission signals for tool condition monitoring (TCM), Acoustical Society of America, ARLO 4(1): 13-18. http://dx.doi.org/10.1121/1.1532370.

4. Li, X. 2002. Abrief review: acoustic emission method for tool wear monitoring during turning, Machine Tools \& Manufacture 42: 157-165. http://dx.doi.org/10.1016/S0890-6955(01)00108-0.

5. Haili, W.; Hua, S.; Ming, C.; Dejin, H. 2003. On-line tool breakage monitoring in turning, Materials Processing Technology 139: 237-242. http://dx.doi.org/10.1016/S0924-0136(03)00227-9.

6. Das, S.; Roy, R.; Chattopadhyayal, A.B. 1996. Evaluation of wear of turning carbide inserts using neural networks, Machine Tools \& Manufacture 36: 789-797. http://dx.doi.org/10.1016/0890-6955(95)00089-5.

7. Kuljanic, E.; Sortino, M. 2005. TWEM a method based on cutting forces monitoring tool wear in face milling, Machine Tools \& Manufacture 45: 29-34. http://dx.doi.org/10.1016/j.ijmachtools.2004.06.016.

8. Rmili, W.; Roger, S.; Ouahabi, A. 2007. Contribution a l'étude de la surveillance de l'usure des outils de coupe en usinage, $18^{\text {éme }}$ Congrès Français de Mécanique, Grenoble, France, 27-31 Août.

9. Babouri, M.K.; Ouelaa, N.; Djebala, A. 2014. Temporal and frequential analysis of the tools wear evolution, Mechanika 20(2): 205-212. http://dx.doi.org/10.5755/j01.mech.20.2.6933.

10. Wang, L.; Mehrabi, M. G.; Kannatey, Asibu Jr. 2001. Tool wear monitoring in reconfigurable machining systems through wavelet analysis, NAMRI/SME Transactions 29: 399-406.

11. Engin, S.N.; Gülez, K. 1999. A wavelet transform artificial neural networks (WT-ANN) based rotating machinery fault diagnostics methodology, Nonlinear Signal and Image Processing. NSIP 9: 714-720.

12. Antić, A.; Hodolic, J.; Sokovič, M. 2006. Development of an intelligent system for tool wear monitoring applying neural networks, Journal of Achievements in Materials and Manufacturing Engineering 14(1-2): 146-151.

13. Huang, N.E.; Shen, Z.; Long, S.R.; Wu, M.C.; Shih, H.H.; Zheng, Q.; Yen, N.C.; Tung, C.C.; Liu, H.H. 1998. The empirical mode decomposition and Hilbert spectrum for nonlinear and non-stationary time series analysis, Proceedings of the Royal Society of London 454: 903-995.

http://dx.doi.org/10.1098/rspa.1998.0193.

14. Silva, R.G.; Reuben, R.L.; Baker, K.J.; Wilcox, S.J. 1998. Tool wear monitoring of turning operations by neural networks and expert system classification of a feature set generated from multiple sensors, Mechanical Systems and Signal Processing 12(2): 319-332. http://dx.doi.org/10.1006/mssp.1997.0123.

15. SANDVIK Coromant, Catalogue Général: Tournage Fraisage - Perçage - Alésage - Attachements, 2007.

\section{K. Babouri, N. Ouelaa, A. Djebala}

\section{APPLICATION OF THE EMPIRICAL MODE DECOMPOSITION METHOD FOR THE PREDICTION OF THE TOOL WEAR IN TURNING OPERATION}

S u m m a r y

Tool wear is one of the factors to consider since its evolution damages and degrades the surface roughness of machined material. For this raison, this article proposes the application of a new time-frequency method, called Empirical Mode Decomposition, for the prediction of the tool wear in turning operation.

The proposed method is applied on vibratory acceleration signals measured during the cutting process in different configurations. The sifting process of the EMD method decomposes the measured signal into several Intrinsic Modes Functions allowing its time-frequency analysis. A time and frequency domain analyses have been carried out.

In time domain, the tool wear monitoring is performed by using two scalar indicators; the energy and the mean power of the first IMF of the EMD decomposition. The variation of these indicators over the entire tool life highlights the three periods and allows locating the transition point between the wear stabilization and the wear acceleration period. The prediction of the tool ageing is then very clear avoiding its collapse and the machining fail.

In the frequency domain a new indicator, based on the amplitude of the peak corresponding to the tool's natural frequency, is proposed. It has been shown that the variation of this indicator over the entire tool life is the same as for the scalar indicators. The three periods are shown and the critical transition point reflecting the beginning of the tool ageing is clearly detectable.

The experimental results are very promising in industrial environment for the implementation of online monitoring system for cutting tool state.

Keywords: Wear; Vibratory signature; EMD; Scalar Indicators, Frequency indicator.

Received December 20, 2014

Accepted April 14, 2017 